\title{
DE GRECIA A NARNIA: LA FÁBULA DEL LEÓN Y EL RATÓN FUERA DE LAS COLECCIONES DE FÁBULAS
}

\author{
ANA MARÍA MARIÑO ARIAS
}

Universidad de León ${ }^{1}$

\section{Resumen}

Las fábulas, además de transmitirse a través de colecciones revisadas y rehechas una y otra vez a lo largo de la historia por diferentes autores, se han incorporado como parte del argumento en otros géneros y tradiciones, con algunos cambios pero conservando su argumento principal. En el presente artículo se estudia de que modo se ha hecho en el caso concreto de la fábula esópica del león y el ratón en tres obras: un cuento anónimo del Antiguo Egipto, el Libro del Buen Amor y Las Crónicas de Narnia.
\end{abstract}

Palabras clave: fábula, león, ratón, Esopo, Egipto, cuento, Libro del Buen Amor, Narnia

\begin{abstract}
Fables have been transmitted through history in thousand times cheked and remade collections by different authors. Besides, they have been attached to the topics of other genres and literary traditions with a few changes but preserving their main story line. This article studies the presence of the esopic fable of the lion and the mouse in three different works: an anonymous tale from the Ancient Egypt, El Libro del Buen Amor and Narnia Chronicles.
\end{abstract}

Key Words: fable, lion, mouse, Esopo, Egypt, tale, Libro del Buen Amor, Narnia

La fábula es un género muy relacionado con la tradición oral y la literatura popular cuya esencia es la brevedad y la intención moral. Además de su condición de género hipertextual, ya que al ser un género menor y un tipo de literatura popular, su tradición textual está abierta, desde la Antigüedad se han traducido, interpretado y recreado las mismas fábulas. Sin embargo, con la tradición va unida la variación, aunque más en la forma que en el tono, pues el armazón lógico y argumental de la fábula es muy rígido.

Antonio Cascón Dorado (1987-88: 74) pone de manifiesto que se producen similares fenómenos de transmisión en la fábula y el exemplum: cambio de personajes, de situaciones argumentales, ampliaciones, abreviaciones, duplicaciones,

${ }^{1}$ Correo-e: khendra@hotmail.es. Recibido: 19-12-2012. Aceptado: 15-03-2013. 
contaminaciones, cambios de intencionalidad..., fenómenos que se aprecian fácilmente al realizar comparaciones entre distintas versiones de la misma fábula.

Pero, además de las modificaciones que se aprecian al comparar las diversas colecciones de fábulas, las fábulas también pueden integrarse como parte del argumento en obras de otros géneros literarios, alterando igualmente algunos de sus elementos en función de las necesidades o intenciones del autor, pero conservando claramente su esencia.

Así pues, a continuación, estudiaremos la forma en que ha sido adaptada una fábula esópica, la fábula del león y el ratón, en tres obras de mayor extensión, de géneros diferentes y de momentos y lugares muy dispares: un cuento egipcio anónimo, el Libro del Buen Amor del Arcipreste de Hita y Las Crónicas de Narnia de C.S. Lewis.

A Esopo no le consideraban los griegos como el inventor del género, sino el introductor en Grecia de la primera colección de fábulas, que fijó el tipo clásico de tales relatos: breves y didácticos, con una estructura narrativa característica. Sobre él se tejió desde muy antiguo una leyenda biográfica, núcleo de la Vida de Esopo, cuya ideología coincide con la que se desprende de la colección de fábulas: Esopo se vale de la astucia para triunfar en un mundo donde imperan la fuerza, el engaño y la lucha constante de unos contra otros, sin más sanción moral que el éxito o el fracaso.

La fábula del león y el ratón en la redacción atribuida a Esopo (H.155) consiste en una sencilla anécdota: un ratón juega con otros hasta que despierta a un león y éste lo coge para a comérselo. El ratón le pide que lo suelte, prometiendo que le pagará el favor y felino accede aunque sin tomarse en serio el ofrecimiento. Un día es apresado por unos cazadores, atado a un árbol y liberado por el ratón que roe la cuerda. Por último se cierra con un parlamento del ratón expresando que también los pequeños tienen gratitud.

El tema fundamental que ilustra esta fábula es el del animal agradecido, desarrollado para poner de manifiesto el desagradecimiento de los hombres. Tema que se repite en otras fábulas empleando otros animales, así como la liberación de elefantes y gacelas por ratones aparecen en fábulas de la India, que pueden ser independientes o derivadas de las griegas. (Rodríguez Adrados, 1987:165)

La egiptóloga Emma Brunner-Traut (2000: 334) considera que esta fábula griega tiene como modelo un cuento egipcio que desarrolla de manera mucho más extensa la trama. Se basa, entre otras cosas, en que en la Vida de Esopo, se sitúa al griego recopilando materiales para sus fábulas en las orillas del Nilo. Sin embargo, Rodríguez Adrados (1987: 725) piensa, por el contrario, que el modelo es la fábula griega, considerando que es ésta la que tiene un origen antiguo mesopotámico, por la estructura de la fábula griega que es perfectamente regular y posiblemente arcaica, dada su organización en dos actos y que en el Pañcatantra existe un paralelo casi exacto, sustituyendo el león por un elefante. Además de que el tema del animal agradecido se encuentra varias veces en tanto en fábulas griegas como indias. 
Este cuento egipcio (Brunner-Traut, 2000: 181) fue redactado en época helenística y transcrito en el siglo II d.C. en caracteres demóticos. En él, un poderoso y aterrador león va recorriendo el desierto buscando al hombre para castigarle por las tropelías que ha hecho a los diversos animales que se va encontrando: una pantera, un caballo y un asno, un toro y una vaca, un oso e incluso a otro león. En su periplo está a punto de pisotear a un ratoncillo que le ofrece salvarle de la desgracia, cosa que el prepotente león se toma a broma pero que, al igual que en la fábula esópica, termina siendo lo que ocurre cuando el felino cae en la red del cazador. Finalmente ambos se marchan juntos de vuelta al desierto.

En la versión de Esopo el ratón se disculpa por su ignorancia al haber molestado al león y es el león el que considera que es indigno de él vengarse de un ser tan pequeño. Sin embargo, en el cuento egipcio, el roedor suplica alegando que si se lo come no saciará su hambre y prometiéndole, casi vaticinándole, que si le perdona la vida algún día podrá devolverle el favor, algo que causa la hilaridad del felino, aunque acaba soltándolo igualmente, pensando que no le iba a llenar el comérselo. La acción y promesa de Esopo se convierten en destino y premonición al imbricarse en un contexto religioso: una conversación en la que el mono mensajero Thot entretiene y aconseja a la diosa leona Tefnut, la gata del sol, durante su peregrinación.

Por tanto, en el caso del cuento egipcio el tema, más que en el agradecimiento en sí, se centra en resaltar la valía de lo que a simple vista parece insignificante: el poderoso y arrogante león, que se dispone a vengar al resto de los animales atropellados por la crueldad del hombre, acaba cayendo en una de las trampas de éste y siendo salvado por un minúsculo ratoncito del que se burló. Así como que, cuando el destino así lo determina, los más débiles pueden ayudar a los más fuertes, algo muy importante en el contexto en el que se enmarca.

Existe otro cuento de Kordofán, al oeste del Alto Nilo, zona de influencia de la tierra de los faraones, derivado del anterior, conservado oralmente y recopilado en el siglo XX por L. Frobenius (Brunner-Traut, 2000: 184). Aquí es el ratón el que provoca al león, resaltando que la inteligencia es preferible a la fuerza y le reta a enfrentarse al hombre, que resulta ser un comerciante de madera que pasaba por allí. El leñador finge aceptar el reto y consigue que el león se deje atar a un árbol, cosa que aprovecha para golpearle con una cuerda. Cuando finalmente el hombre se marcha, el ratón accede a desatar al león tras lograr que le prometa amistad eterna. El león intenta vengarse pero termina escaldado, literalmente, y cuando vuelve a ver al ratón intenta comérselo culpándolo de la situación en la que se haya pero el roedor logra zafarse de la presa con astucia. Tiempo después y tras varias tretas más, el leñador termina consiguiendo que ese león y toda una manada de leones le jure estar a su servicio.

A pesar de la independencia de la trama, los elementos esenciales idénticos llevan a la conclusión de que no han podido ser creados de forma independiente. El distinto ambiente cultural y el diferente estado de ánimo explican el aumento de la crueldad y el sentido final del cuento, explicar la relación entre los faraones y los leones, no solo 
símbolo de soberanía, también acompañantes y protectores en la guerra. (BrunnerTraut, 2000:335)

En ambos casos se mantienen varios elementos de la fábula original: los protagonistas, el león y el ratón, si bien en los cuentos se incluye la presencia humana, y también el tema de la crueldad, ausentes en el texto griego. El cuento egipcio no incluye el apresamiento del roedor sino que el felino casi lo pisa pero en el de Kordofán sí ocurre, así como el hecho de que el punto inicial de la trama sea que el ratón molesta al león, aunque de distinta forma. Sin embargo, a diferencia de la fábula, esa prisión del ratón sucede después de la liberación de las cuerdas del león por el ratón y rompiendo el felino así, su promesa de amistad eterna al roedor. Además, éste se libra de las garras no con promesas sino con ayuda de su ingenio y aprovechando el miedo que en ese momento le tiene el león al hombre.

La recepción medieval de la obra de Esopo fue trazada hace más de un siglo por Hervieux (1970) en su extenso estudio acerca de los fabulistas latinos, desde la época de Augusto hasta finales de la Edad Media. Se produce bien por medio de Fedro, en latín, sobre todo a través de la versión en prosa latina del Romulus, bien mediante la obra de Babrio, en griego, y especialmente mediante la versión en dísticos elegiacos latinos de Aviano. Ello determina la existencia en este periodo de dos líneas de transmisión de las fábulas esópicas, a las que los distintos recopiladores irán añadiendo otras de distintas procedencias, haciendo que, de ciento cincuenta, pasen a ser más de doscientas fábulas.

En esta época, Esopo pertenecía al grado inferior de los "auctores minores", empleado para la enseñanza de la gramática y de la retórica, dado que sus fábulas, gracias a su brevedad, sencillez y fácil moralización, eran un adecuado material didáctico. Con esta orientación surge el "Esopo moralizado", una versión latina versificada en la que se cristianizan las fábulas y se adaptan al uso escolar medieval. Se atribuye al poeta Walter el Inglés o Gualterius Ánglicus, del siglo XII, que se sirvió del Romulus vulgaris (o Recensio gallicana, del siglo V o VI), el más difundido de los Romuli en prosa. El supuesto autor, Romulo, no conoció la obra de Esopo, sino la tradición latina de Fedro, cuyas fábulas parafrasea y reorganiza, a la que añade otros materiales y nuevas fábulas creadas a partir de la imitación del estilo de Fedro. Estas fábulas de Gualterius Ánglicus, como obra de lectura obligatoria en la clase del grammaticus, se difundieron en la Edad Media por medio de comentarios que acompañaron a los dísticos originales desde finales del siglo XIII.

El Arcipreste de Hita se basó mayoritariamente en esta obra, aunque en algunos casos parece alejarse de ella por manejar un manuscrito con glosas interlineales y extensos comentarios, en las fábulas que pone en boca de las protagonistas principales en el episodio de doña Garoza en el Libro del Buen Amor, como ha estudiado Bienvenido Morros (2003). A lo largo de dos días la alcahueta Trotaconventos y la monja amada por el arcipreste, intercambian diez fábulas que sirven para ilustrar sus opiniones contrapuestas, si bien no siempre se establece claramente la relación entre el contenido de las fábulas y la situación a la que pretenden aplicarlas. Es bastante probable que esto se deba a que el autor otorga más importancia a las interpretaciones morales de 
los comentaristas de los hexámetros de Gualterio que a la literalidad de lo expuesto por la fábula (Morros, 2003: 431).

En el presente caso, la fábula del león y el ratón, Juan Ruiz se ciñe bastante al texto de Ánglico y sólo recurre a las glosas interlineales cuando el texto no es suficientemente claro (Morros, 2003: 417).

No obstante, el papel del protagonista, aunque continúa siendo positivo, no lo es tanto como en la versión de Gualterio. Esto responde a que la fábula está narrada por Trotaconventos, que se identifica con el ratón mientras atribuye a doña Garoza el papel del león, de ahí que sea el primero el que muestra mayor ingenio y capacidad discursiva, como ha señalado Luzdivina Cuesta (2010: 483).

Así pues, nos encontramos con una versión de esta fábula en el Enxiemplo del león e del mur (1425-1436) puesto en boca de la alcahueta en el momento en que sus anteriores propuestas, también expresadas a través de fábulas, han despertado la ira de la monja. El miedo a la mal velada amenaza inspira ala vieja a aprovechar y reforzar, con los elocuentes argumentos del ratón, la enseñanza moral del escaso honor que supone para el grande el hecho de vencer al pequeño, presente especialmente en la interpretación de Gualterio de la fábula del león y el ratón.

Además el comentarista de Ánglico identificaba al león con el rico y al ratón con el pobre y especificaba que el pobre puede resultar de gran utilidad en el aspecto religioso al rico, conociendo el trato que los evangelios otorgan al menesteroso. De este modo, Trotaconventos pretende, al identificarse con el ratón, dar cuenta de su utilidad en cualquier circunstancia, ofreciendo, a cambio de poder y riqueza, su entendimiento y astucia. Sin embargo, se mantiene la ambigüedad de toda la obra, por lo que se abstiene de aclarar con qué propósito, si para afianzar y consolidar su amor por Dios o si, por el contrario, pretende invitarla a valerse de su astucia e inteligencia para eludir el castigo de incurrir en el pecado del loco amor (Morros, 2003: 439).

Cuando Clive Staples Lewis, profesor de Lengua y Literatura Inglesas en la prestigiosa Universidad de Oxford, publicó en 1950 El león, la bruja y el armario, la primera de siete novelas de Las Crónicas de Narnia (1950-1956), era un autor académico de gran relieve por sus estudios eruditos de Literatura Renacentista Inglesa y sus reflexiones sobre la condición humana².

Su amplia formación académica, unida a su pasión por la lectura desde la infancia, hace que, en ocasiones, en su obra aparezca una amalgama de elementos e influencias dispares, hasta el punto que su amigo, colega y también creador de obras de fantasía, J.R.R. Tolkien, no comprendía cómo Lewis había podido escribir algo tan poco coherente y menos aún, cómo a pesar de ello había triunfado.(Carpenter,

\footnotetext{
${ }^{2}$ Lewis fue profesor de literatura inglesa medieval y renacentista prácticamente toda su vida. Fue fellow en el Magdalen College y miembro del consejo de Gobierno de la Universidad de Oxford entre 1925 y 1954 (29 años) y en 1954 fue nombrado profesor en la Universidad de Cambridge, en la cual enseñó hasta su muerte en 1963 (9 años). Es decir, dedicó 38 años a la academia, de los 65 que el escritor pasó por este mundo.
} 
2008:357) Y esto, teniendo en cuenta que el germen de Narnia fue el resultado de echar a suertes la decisión de quien de ellos escribiría una novela basada en un viaje espacial (Lewis) y quien en uno temporal (Tolkien). (Carpenter, 1993:516, 567)

Narnia es un mundo imaginario, poblado por personajes de muy distintas fuentes, creado en El sobrino del mago (1955) por el único personaje que aparece en toda la saga, Aslan, un gran león, cosa que no resulta nada sorprendente dado que su nombre es la traducción de león en turco.

La elección de un león como personaje fundamental puede atribuirse a múltiples motivos e influencias, desde la astrología, el mundo clásico, el culto de Mitra, la heráldica... Pero en este caso, es más que evidente la conexión de la imagen del león conla figura de Cristo, al igual que en los Bestiarios medievales y en una larga tradición literaria y teológica. En palabras del propio autor en una carta: "Le di forma de león porque se supone que el león es el rey de las bestias, y Cristo es el León de Judá mencionado en la Biblia." ${ }^{3}$

No obstante, también podemos rastrear una clara influencia de la fábula esópica, que probablemente leyó en su infancia, fascinado como estaba con las historias cuyos protagonistas eran animales, como las de Beatrix Potter. (Carpenter, 2008, 21) En concreto, en El león, la bruja y el armario encontramos rastros de dos fábulas esópicas más, aparte de la del león y el ratón, en las que los leones son la clave.

En primer lugar, la del león como rey de las bestias (H. 179). Se trata de un reinado idílico en el que los fuertes dan cuenta de sus actos a los débiles y todos los animales son felices. En Narnia lo vemos reflejado en la profecía del castor:

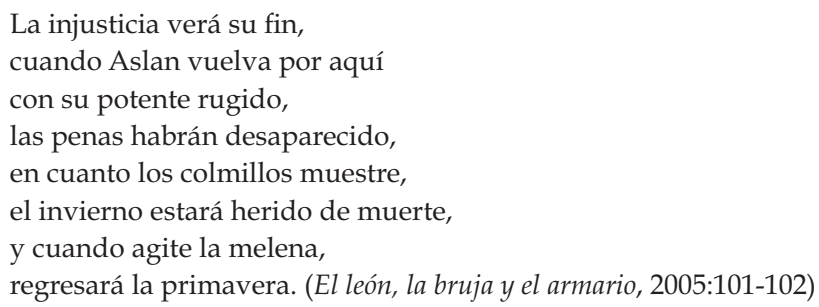

También se aprecia con claridad, el rastro de la fábula del león viejo y débil (H. 201) que ha de soportar el escarnio y las injurias de los otros animales, ahora que ya no es temido hasta que la frustración le lleva a clavarse sus propias garras en el pecho para matarse. En este caso, y siguiendo la línea de la alegoría cristológica, Aslan se entrega voluntario como víctima sacrificial para salvar a uno de los niños protagonistas. Esto propicia que, aprovechando su debilidad al permitir que le aten, las malévolas y bajas criaturas pierden el temor y le golpean y afeitan antes de matarlo clavándole un cuchillo de piedra en el corazón, dado que la salida del suicidio sería impensable en el contexto cristiano en el que nos movemos.(El león, la bruja y el armario, 2005:189-193)

\footnotetext{
${ }^{3}$ Una carta inédita del autor de estos libros revela la evidencia clara y contundente del mensaje que él quiso plasmar en Las Crónicas de Narnia. Esta carta, con fecha del año 1961, fue enviada por C. S. Lewis a un niño que leía sus historias y ha sido divulgada por Walter Hooper, quien fue secretario de Lewis y se convirtió en su biógrafo.
} 
Incluso en el último volumen de la saga, La última batalla (1956), el conflicto se articula en torno a la fábula del asno vestido con la piel de león y los problemas y confusiones que provoca al hacerse pasar por Aslan.

Pero, volviendo a la fábula que nos ocupa, la del león y el ratón, su presencia en la trama es evidente, si bien modificada y adaptada a las necesidades del relato en el que se inserta.

Tras el sacrificio del león en la Mesa de Piedra, los asesinos se marchan dejando el cadáver atado y es en ese momento cuando aparecen cientos de minúsculas formas grises que resultan ser ratones que llegan para roer las cuerdas que aprisionan al gran felino.

Es llamativo el hecho de que la primera reacción de una de las dos niñas protagonistas de la obra, que están llorando la muerte del león, sea la de rechazar a los roedores y apartarlos del cadáver de su amigo. Emplea además los adjetivos "asquerosos", "horribles" y "mugrientos" antes de intentar apartarlos. Finalmente, al percatarse, gracias a su hermana, de la actividad a la que estaban entregados, les permiten continuar, si bien mencionan la inutilidad de tal acción.

De este modo, se ha suprimido la primera parte del argumento original: la del ratón preso que recibe la merced del perdón del león. El hecho de no existir la deuda de vida que origina la salvación del león de la red que lo aprisiona, permite la aparición de un nuevo componente ausente en las versiones anteriores: la gratitud del león, posible gracias a la resurrección del gran felino al amanecer y que, además, contribuye a aumentar los rasgos positivos de la figura del león, muy adecuado dado que representa al Mesías cristiano.

El príncipe Caspian (1951), la siguiente novela publicada, incorpora unos peculiares personajes: doce ratones que ayudan a pelear al protagonista, el príncipe Caspian contra el usurpador Miraz, su tío. Son más grandes de lo habitual, tienen largas orejas y portan espadas con aire marcial, de modo que, al conocerlos, Caspian tuvo que esforzarse para no reírse de su ofrecimiento de ayuda y tampoco se les permite ser jueces en el duelo entre Miraz y el rey Peter. Sin embargo, durante la batalla desempeñan un papel fundamental: clavan sus estoques en los pies de los enemigos, haciendo que caigan y estorbándoles.

A pesar de su valor, Reepicheep, su líder, resulta muy mal herido y aunque logran curarle, pierde su cola en la batalla. Un hecho que parece nimio a los ojos de los demás pero que supone un gran deshonor para ellos, por lo que suplican a Aslan que se la devuelva o todos ellos se cortarán las colas en solidaridad con su jefe. Es en este momento cuando Aslan informa de cómo pagó su deuda con los ratones que le liberaron de las cuerdas: otorgándoles el don del habla. Y como nueva muestra de gratitud, ya que estos son los descendientes de aquellos, y asombrado por la solidaridad de los ratones, decide devolver la cola perdida al jefe de los roedores, pese a que le parece excesiva su obsesión por el honor (El príncipe Caspian, 2005: 265-268). 
Así pues, estos pequeños animalillos se han elevado, con su acción liberadora de las ataduras del felino, desde los denigrantes calificativos que Susan les dedica en el primer libro: "ratones horribles" y "criaturas mugrientas", a seres provistos de honor y que resultan de gran importancia. Su valía es tal que, en La travesía del Viajero del Alba (1952), nos informan de que Reepicheep recibió la profecía de una dríade al nacer. Al final de la obra, desembarca en su propio bote miniatura, desaparece y nos dan a entender que finalmente llega al País de Aslan, una especie de Paraíso, igual que Narnia pero sin defectos. Incluso se le llega a equiparar con la figura de San Pedro debido a su papel como personaje que da la bienvenida a los que llegan a este Paraíso en La última batalla (1956), cuando asistimos al final de Narnia.

De este modo, como vemos, el elemento central del ratón que libera al león de las ataduras que le aprisionan se mantiene, así como el del agradecimiento presente en la fábula esópica y el hecho de que, aunque algo parezca insignificante, como un ratón, puede resultar de utilidad a alguien que, a priori, es muchísimo más poderoso, al igual que en todos los casos anteriores. Si bien, al no existir la deuda de vida anterior por parte del roedor, lo que nos encontramos es el encumbramiento del ratón en una figura honorable, generosa, valiente y profundamente espiritual, cualidades que, ni en las fábulas, ni en el imaginario colectivo, son atribuidas jamás a los ratones.

Llegados a este punto, hemos podido observar que el armazón argumental principal se ha mantenido en los tres casos estudiados: la liberación del león de sus ataduras. Así como la doble enseñanza de la fábula, elemento esencial del género dado su afán didáctico: el valor potencial de lo que parece insignificante y el hecho de que ninguna buena acción queda sin recompensa, con independencia de que la recompensa sea del ratón al león o al contrario.

Pero, pese a ello, cada autor ha podido jugar con los elementos y adaptarlos en función de sus necesidades o intenciones. Cada uno, sin duda, ha proporcionado un estilo específico y característico a esas composiciones, reforzado algunos elementos, suprimiendo otros, ampliando la trama...y aun así, la fábula ha logrado mantener su esencia y su vigencia a través del tiempo, el espacio o el idioma.

\section{BIBLIOGRAFÍA}

Bestiario Medieval (1999), Madrid, Siruela.

Blecua, A. (Ed.) (1992): Libro del Buen Amor, Madrid, Cátedra.

Brunner-Traut, E. (2000): Cuentos del Antiguo Egipto, Madrid, Edaf.

Carpenter, H (2008): Los Inklings, Barcelona BibliothecaHomolegens.

Carpenter, H (1993): Cartas de J. R. R. Tolkien, Barcelona, Minotauro.

Cascón Dorado, A. (1987-1988): “Fenómenos comunes en la trasmisión del exemplum y la fábula", Habis18-19:173-185.

Cuesta Torre, M. L. (2008): “El ensiemplo del león y del caballo y la crítica a la caballería en el Libro de Buen Amor", Boletín de la Biblioteca Menéndez Pelayo, 84: 109-133. 
Cuesta Torre, M. L. (2012): “Las fábulas esópicas sobre leones del Libro del Buen Amor", en Natalia Fernández Rodríguez y María Fernández Ferreiro (eds.): 477-487.

Deyermond, A. (2007): “Leones y tigres en la literatura medieval castellana”, en A. López y L Cuesta (eds.): 41-63.

Fernández Rodríguez, N. y M. Fernández Ferreiro (2012): Literatura Medieval y Renacentista en España: líneas y pautas, Salamanca, Gráficas Cervantes.

Fradejas Rueda, J.M. et alii (2010): Actas del XIII Congreso Internacional de la Asociación Hispánica de Literatura Medieval, Valladolid, Universidad y Ayuntamiento de Valladolid.

García Gual, C. (1978): Introducción a Fábulas de Esopo - Vida de Esopo - Fábulas de Babrio, Madrid, Gredos.

Hervieux, L (1970): Les Fabulistes latins, depuis le siècle d'Auguste jusqu'à la fin du Moyen Âge. Vol. 2, Phèdre et ses anciens imitateurs directs et indirects, II. Paris. FirminDidot. 5 vols. reimp.Hildesheim. Georg Olms.

Lacarra, M.J. (2009): “Fábulas y proverbios en el Esopo anotado", Revista de poética medieval, 23: 297-329.

Lacarra, M.J. (2010): “La fortuna del Isopete en España”, en J.M. Fradejaset alii (eds.): 109-134.

Lewis, C.S. (2005): El león, la buja y el armario, Barcelona, Círculo de Lectores.

Lewis, C. S. (2005): El sobrino del mago, Barcelona, Círculo de Lectores.

Lewis, C.S. (2005): El príncipe Caspian, Barcelona, Círculo de Lectores.

Lewis, C.S. (2005): La travesía del viajero del Alba, Barcelona, Círculo de Lectores.

Lewis, C.S. (2005): La última batalla, Barcelona, Círculo de Lectores.

López Castro, A. y Cuesta Torre, M. L. (2007): Actas del XI Congreso Internacional de la Asociación Hispánica de Literatura Medieval, León, Universidad de León.

Morros Mestre, B. (2003): “El episodio de doña Garoza a través de sus fábulas (Libro del Buen Amor, 1332-1507), Nueva Revista de Filología Hispánica, 2: 417-464.

Pérez Díez, M.C. (2004): Por Siempre Jamás: C.S. Lewis y la Tierra de Narnia, León, Universidad de León.

Rodríguez Adrados, F. (1987): Historia de la fábula greco-latina, Madrid, Universidad Complutense. 